\title{
Prevalence of overweight and obesity among adolescents in Irbid governorate, Jordan
}

\author{
N.N. Abu Baker ${ }^{7}$ and S.M. Daradkeh ${ }^{7}$
}

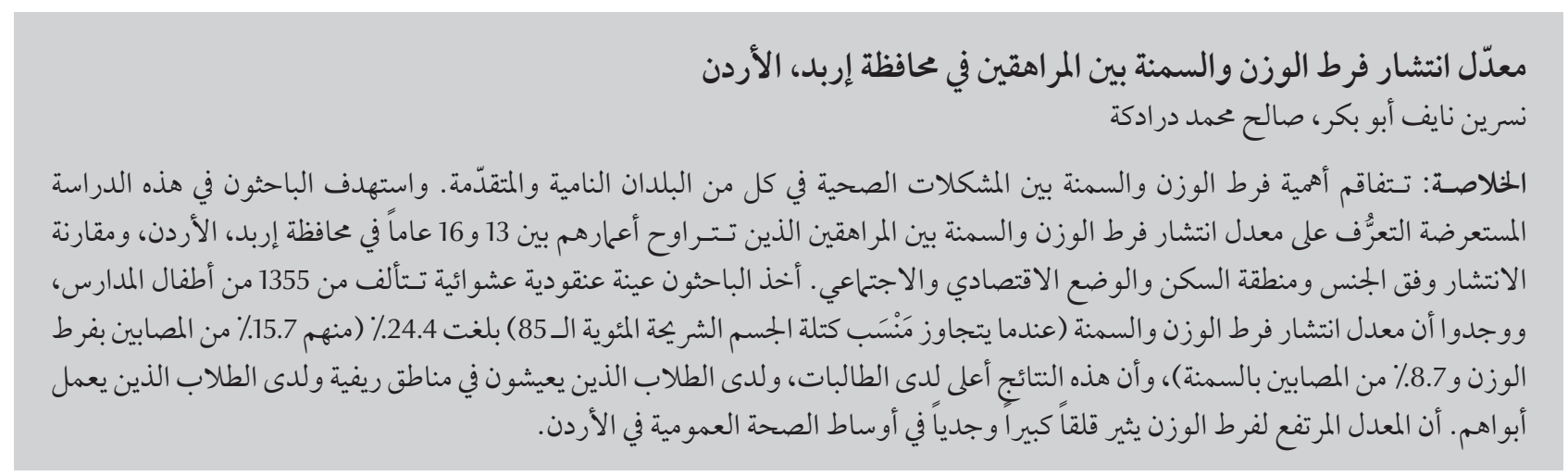

ABSTRACT Overweight and obesity is an escalating health problem in both developed and developing countries. This descriptive cross-sectional study aimed to determine the prevalence of overweight and obesity among adolescents aged 13-16 years in Irbid governorate, Jordan, and to compare the prevalence by sex, residential area and socioeconomic status. In a cluster random sample of 1355 school students the prevalence of overweight and obesity (body mass index $\geq 85$ th percentile) was $24.4 \%$ (15.7\% overweight and $8.7 \%$ obese) and was significantly higher among female students, students who lived in urban areas and those with working parents. This high prevalence of overweight is a serious concern for public health in Jordan.

\section{Prévalence de la surcharge pondérale et de l'obésité chez les adolescents du gouvernorat d'Irbid (Jordanie)}

RÉSUMÉ La surcharge pondérale et l'obésité sont un problème grandissant dans les pays industrialisés comme dans les pays en développement. Le but de cette étude descriptive transversale était de déterminer la prévalence de la surcharge pondérale et de l'obésité chez les adolescents âgés de 13 à 16 ans dans le gouvernorat d'Irbid (Jordanie), et d'établir des comparaisons en fonction du sexe, de la zone de résidence et du statut socioéconomique. Dans un échantillon aléatoire de grappes de 1355 élèves, la prévalence de la surcharge pondérale et de l'obésité (indice de masse corporelle $\geq 85$ e percentile) était de 24,4\% (dont 15,7\% en surcharge pondérale et 8,7 \% souffrant d'obésité). Elle était significativement supérieure chez les filles, les élèves vivant dans des zones urbaines et ceux dont les parents travaillent. Cette prévalence élevée de la surcharge pondérale fait peser de graves inquiétudes sur la santé publique en Jordanie. 


\section{Introduction}

Overweight and obesity is an escalating health problem in both developed and developing countries. The International Obesity Task Force report showed that 1 in 10 children worldwide is overweight; a total of 155 million children and adolescents are overweight and around 30-45 million are classified as obese [1]. The main contributing forces in the increasing prevalence of overweight and obesity are believed to be increasing urbanization and the globalization of food markets. With rising incomes and urbanizing populations, physical activity levels tend to decline and diets increasingly shift to include foods higher in saturated fats and sugars [2].

Overweight and obesity are risk factors for many health problems, regardless of a person's age. Children and adolescents who are overweight and obese, however, face a greater risk of health problems - including type 2 diabetes mellitus, high blood pressure, high blood lipids, asthma, sleep apnoea, orthopaedic problems and psychosocial problems - than their normal weight peers [3]. There is an urgent need to investigate the magnitude of this problem in developing countries such as Jordan, and to implement prevention strategies as early as childhood by involving families, schools and the whole community.

National estimates of the prevalence of overweight and obesity among adolescents are currently unavailable in Jordan. One study in 1997 found that the overall prevalence of obesity among semi-urban communities in Jordan was $49.7 \%$ (32.7\% in males and 59.8\% in females) [4]. The objectives of the present study were to determine the prevalence of overweight and obesity among adolescent school students aged 13-16 years in Irbid governorate, Jordan, and to compare the prevalence by sex, residential area and socioeconomic status. Such data will provide health care providers and school administrators with useful information about the prevalence and factors associated with overweight and obesity in order to design prevention strategies for adolescents.

\section{Methods}

A descriptive, exploratory crosssectional design was used to estimate the prevalence of overweight and obesity among adolescents in Irbid governorate.

\section{Study setting}

Data collection was conducted in the primary and secondary schools of Irbid governorate (male and female, public and private schools). Irbid is situated in the north-west of Jordan, $80 \mathrm{~km}$ to the north of the capital, Amman. The total population of Jordan is around 5800000 [5], with more than 25\% aged 10-19 years. Approximately $18 \%$ of the Jordanian population reside in Irbid governorate, around 30\% in rural areas [6]. About $99 \%$ of Jordanian children of school age attend primary school and drop-out rates in secondary school are very low $[6]$.

\section{Sample}

The population for this study was all students aged 13-16years old (i.e. 8th, 9th and 10th school grades) in all Irbid educational directorates. A cluster random sample was used. A list of public schools was obtained from the education directorates and clusters were created for each of the 7 directorates, then clusters were created for male and female schools and 2 schools were selected randomly from each cluster (1 girls' school and 1 boys' school). Finally, 3 classes from each school were selected randomly, 1 section for each grade (8th, 9 th and 10th). Private schools were only present in 2 of the directorates. A list of private schools in each directorate was created and 2 schools were randomly selected from each list. The total number of schools used for data collection was 18 . The total sample size was 1355 participants aged 13-16 years, based on the following formula: $N$ $=\left[(1.96)^{2} \times p q\right] / d^{2}$, where $N=$ sample size, $p=$ expected prevalence, $q=1-p, d$ $=$ margin of error

To calculate the $95 \%$ confidence interval for an expected prevalence of $25 \%$ (based on the average percentage prevalence of overweight and obesity in the world) with a margin of error (d) of not more than 0.03 , the required sample size was 800 . To cover for nonparticipation, we enlarged the sample as follows: $N=(1.96)^{2} \times(0.25) \times(1-0.25) /$ $(0.03)^{2}=800$.

\section{Data collection}

Each student who agreed to participate was interviewed first to collect sociodemographic data using a structured questionnaire, and then the student's weight and height were recorded. To eliminate interviewer bias, the study was conducted by 1 interviewer only in May 2007.

The following sociodemographic were collected: age, sex, education level of student (8th, 9th or 10th grade), residence (urban/rural), family income, parents' education level and parents' employment status. For the purpose of this study a rural area was defined as a sparsely settled place away from the influence of large cities and having an agricultural character. Urban area was defined as the area with an increased density of human-created structures in comparison to the areas surrounding it and further developed by the process of urbanization. Low family income was defined as $\leq 200$ Jordanian dirhams (JD) per month, middle income as 201-600 JD per month and high income as $\geq 600 \mathrm{JD}$ per month. When a student was unable to identify the family income level the response was recorded as "don't know". Students were asked if their father and mother had a job or not; the type of job was not recorded. These variables were selected because they could easily be reported by this age 
group. Other variables such as exercise were not collected because they are hard to quantify accurately by self-report in this age group, and they were beyond the scope of this study.

Anthropometric measurements were taken from all participants after the interview. Body weight of the student in light clothing and with bare feet or stockings was measured with a digital scale to the nearest $0.1 \mathrm{~kg}$, and height without shoes was measured by a wallmounted stadiometer and recorded to the nearest $0.5 \mathrm{~cm}$. The reliability of the anthropometric measures was checked during the data collection period and the digital scale was calibrated and checked daily.

Body mass index (BMI) was calculated from the weight $(\mathrm{kg}) /$ height $^{2}$ $\left(\mathrm{m}^{2}\right)$. Overweight and obesity were categorized according to age-sex specific percentiles of BMI using the Centers for Disease Control BMI-forage growth charts [7]: underweight (BMI < 5th percentile); normal weight (BMI 5th-<85th percentile), overweight (BMI 85th-<95th percentile) or obesity (BMI $\geq 95$ th percentile).

\section{Ethical considerations}

Confidentiality was maintained by data coding. Approval to conduct the study in schools was obtained from the department of research at the Ministry of Education. An informed consent was obtained from each participant. Participants were informed about the purpose of the study, that their participation was voluntary and that their anonymity was assured. The data collection process was done separately in a private room for each student to ensure privacy.

\section{Data analysis}

SPSS, version 15 was used to analyse the data. Descriptive statistics such as means, standard deviations (SD) and frequencies were used. Chi-squared analysis was performed to test the association between variables. $P<0.05$ was considered as the cut-off value for significance.

\section{Results}

\section{Description of the sample}

Only 2 students refused to participate in the study, giving a response rate of 98.9\%. Of the 1355 who participated, $55.6 \%$ were female [mean age 14.8 (SD $0.9)$ years] and $44.4 \%$ were male [mean age 14.8 (SD 0.9) years]. About onefifth of the sample were from private schools, and a majority (70.8\%) were from rural areas (Table 1).

One-third of the sample (32.0\%) reported having a low family income, $37.5 \%$ middle income and $11.0 \%$ high income, while $19.3 \%$ did not know their family income.

The children's reports of their parents' education level were that $34.0 \%$ of fathers and $38.0 \%$ of mothers had an educational level below high school while $32.8 \%$ of the fathers and $29.5 \%$ of the mothers had above high-school education. Just over two-thirds of the fathers had jobs (68.1\%), while only $16.4 \%$ of the mothers had jobs (Table 1).

\section{Prevalence of overweight and obesity}

Data on BMI showed that $4.3 \%$ of the total sample was underweight, $71.3 \%$ normal weight, $15.7 \%$ overweight and $8.7 \%$ obese. Thus, the overall prevalence of overweight and obesity among these adolescents was $24.4 \%$. The rate of overweight and obesity was highest among students aged 13 years (31.8\%) and the rate obesity was the lowest among students aged 16 years $(23.0 \%)$ (Table 2).

\section{Prevalence of overweight and obesity by sex}

There was a statically significant difference between males and females in terms of overweight $\left(\chi^{2}=23.7, \mathrm{df}=1, P<0.001\right)$ and obesity $\left(\chi^{2}=7.63, \mathrm{df}=1, P=0.006\right)$. The prevalence of overweight was higher in female (18.9\%) than male students (11.8\%) (Table 2). However, the prevalence of obesity among males (12.3\%) was higher than females (5.8\%).

\begin{tabular}{|c|c|c|}
\hline \multicolumn{3}{|c|}{$\begin{array}{l}\text { Table } 1 \text { Demographic data of the } \\
\text { sample of adolescents }(n=1355)\end{array}$} \\
\hline Demographic data & No. & $\%$ \\
\hline \multicolumn{3}{|l|}{ Age (years) } \\
\hline 13 & 63 & 4.6 \\
\hline 14 & 468 & 34.5 \\
\hline 15 & 437 & 32.3 \\
\hline 16 & 387 & 28.6 \\
\hline \multicolumn{3}{|l|}{ School grade } \\
\hline 8th & 487 & 35.9 \\
\hline 9th & 458 & 33.8 \\
\hline 10th & 410 & 30.3 \\
\hline \multicolumn{3}{|l|}{ Sex } \\
\hline Male & 602 & 44.4 \\
\hline Female & 753 & 55.6 \\
\hline \multicolumn{3}{|l|}{ Residential area } \\
\hline Rural & 959 & 70.8 \\
\hline Urban & 396 & 29.2 \\
\hline \multicolumn{3}{|l|}{ School } \\
\hline Private & 273 & 20.1 \\
\hline Public & 1082 & 79.9 \\
\hline \multicolumn{3}{|l|}{ Family income $^{a}$} \\
\hline Low & 436 & 32.2 \\
\hline Middle & 508 & 37.5 \\
\hline High & 149 & 11.0 \\
\hline Don't know & 262 & 19.3 \\
\hline \multicolumn{3}{|l|}{$\begin{array}{l}\text { Father's education } \\
\text { level }\end{array}$} \\
\hline Below high school & 461 & 34.0 \\
\hline High school & 450 & 33.2 \\
\hline Above high school & 444 & 32.8 \\
\hline \multicolumn{3}{|l|}{$\begin{array}{l}\text { Mother's education } \\
\text { level }\end{array}$} \\
\hline Below high school & 515 & 38.0 \\
\hline High school & 440 & 32.5 \\
\hline Above high school & 400 & 29.5 \\
\hline \multicolumn{3}{|l|}{ Father employed } \\
\hline Yes & 923 & 68.1 \\
\hline No & 432 & 31.9 \\
\hline \multicolumn{3}{|l|}{ Mother employed } \\
\hline Yes & 222 & 16.4 \\
\hline No & 1133 & 83.6 \\
\hline
\end{tabular}

${ }^{a}$ Low $\leq 200$ JD per month; middle 201-600 JD per month; high $\geq 600$ JD per month.

\section{Prevalence of overweight and obesity by living area}

There was a statistically significant difference between adolescents living in urban areas and those living in rural areas in terms of overweight $\left(\chi^{2}\right.$ $=33.9, \mathrm{df}=1, P<0.001)$ and obesity $\left(\chi^{2}=4.88, \mathrm{df}=3, P=0.027\right)$. The 


\begin{tabular}{|c|c|c|c|c|c|c|c|c|c|}
\hline \multirow[t]{2}{*}{ Demographic data } & \multicolumn{2}{|c|}{ Underweight } & \multicolumn{2}{|c|}{ Normal } & \multicolumn{2}{|c|}{ Overweight } & \multicolumn{2}{|c|}{ Obesity } & \multirow{2}{*}{$\begin{array}{c}\text { Total } \\
\text { No. }\end{array}$} \\
\hline & No. & $\%$ & No. & $\%$ & No. & $\%$ & No. & $\%$ & \\
\hline \multicolumn{10}{|l|}{ Age (years) } \\
\hline 13 & 2 & 3.2 & 41 & 65.1 & 10 & 15.9 & 10 & 15.9 & 63 \\
\hline 14 & 20 & 4.3 & 327 & 69.9 & 78 & 16.7 & 43 & 9.2 & 468 \\
\hline 15 & 20 & 4.6 & 316 & 72.3 & 65 & 14.9 & 36 & 8.2 & 437 \\
\hline 16 & 16 & 4.1 & 282 & 72.9 & 60 & 15.5 & 29 & 7.5 & 387 \\
\hline \multicolumn{10}{|l|}{$\operatorname{Sex} x^{a}$} \\
\hline Male & 37 & 6.1 & 420 & 69.8 & 71 & 11.8 & 74 & 12.3 & 602 \\
\hline Female & 21 & 2.8 & 546 & 72.5 & 142 & 18.9 & 44 & 5.8 & 753 \\
\hline \multicolumn{10}{|l|}{ Residential area ${ }^{b}$} \\
\hline Rural & 41 & 4.3 & 699 & 72.9 & 150 & 15.6 & 69 & 7.2 & 959 \\
\hline Urban & 17 & 4.3 & 267 & 67.4 & 63 & 15.9 & 49 & 12.4 & 396 \\
\hline Total & 58 & 4.3 & 966 & 71.3 & 213 & 15.7 & 118 & 8.7 & 1355 \\
\hline
\end{tabular}

${ }^{a} \chi^{2}=23.7, d f=1, P<0.001$ (overweight) $; \chi^{2}=7.63, d f=1, P=0.006$ (obesity).

${ }^{b} \chi^{2}=33.9, d f=1, P<0.001$ (overweight); $\chi^{2}=4.88, d f=3, P=0.027$ (obesity).

prevalence of overweight and obesity was $22.8 \%$ among adolescents living in rural areas and $28.3 \%$ in urban areas. The prevalence of obesity was higher in urban (12.4\%) than in rural areas (7.2\%) (Table 2).

\section{Prevalence of overweight and obesity by socioeconomic status}

The prevalence of overweight and obesity in the present study among students in low, moderate and high income families was $19.9 \%, 24.65 \%$ and $28.2 \%$ respectively. However, there was no statistically significant association between weight and family income $\left(\chi^{2}=13.31\right.$, $\mathrm{df}=12, P=0.35)($ Table 3$)$.

The prevalence of overweight and obesity was higher (26.3\%) among adolescents with working fathers than those with nonworking fathers (20.4\%) and was also higher (26.2\%) among adolescents with working mothers than those with nonworking mothers (24.1\%) (Table 4). The differences between adolescents with working fathers and nonworking fathers was statistically significant for overweight $\left(\chi^{2}=47.9, \mathrm{df}=\right.$ $1, P<0.001)$ and for obesity $\left(\chi^{2}=24.7, \mathrm{df}\right.$ $=1, P<0.001)$. Similarly, there was a statistically significant difference between adolescents with working mothers and nonworking mothers for overweight $\left(\chi^{2}\right.$ $=24.7, \mathrm{df}=1, P<0.001)$ and obesity $\left(\chi^{2}\right.$ $=22.9, \mathrm{df}=1, P<0.001)$.

The prevalence of overweight and obesity was the highest among adolescents who had mothers and fathers with higher education $(29.3 \%$ and $28.6 \%$ respectively). However, there was no statistically significant association between overweight and father's education level $\left(\chi^{2}=17.25, \mathrm{df}=12, P=0.14\right)$ or mother's education level $\left(\chi^{2}=15.78\right.$, df $=12, P=0.20)$.

\section{Discussion}

Overweight and obesity is considered to be an epidemic in many developed and developing countries of the world. The prevalence varies greatly by age group, sex and socioeconomic status [8]. Using the CDC BMI-for-age sex-specific charts, the prevalence of overweight and obesity in this sample of adolescent students aged $13-16$ years old was $24.4 \%$ ( $15.7 \%$ overweight and $8.7 \%$ obese).

Our study indicates that overweight and obesity is a major health problem in

\begin{tabular}{|c|c|c|c|c|c|c|c|c|c|}
\hline \multirow[t]{2}{*}{ Family income ${ }^{a}$} & \multicolumn{2}{|c|}{ Underweight } & \multicolumn{2}{|c|}{ Normal } & \multicolumn{2}{|c|}{ Overweight } & \multicolumn{2}{|c|}{ Obesity } & \multirow{2}{*}{$\begin{array}{c}\text { Total } \\
\text { No. }\end{array}$} \\
\hline & No. & $\%$ & No. & $\%$ & No. & $\%$ & No. & $\%$ & \\
\hline Low & 20 & 4.6 & 329 & 75.5 & 59 & 13.5 & 28 & 6.4 & 436 \\
\hline Medium & 23 & 4.5 & 358 & 70.5 & 79 & 15.6 & 48 & 9.4 & 508 \\
\hline High & 6 & 4.0 & 101 & 67.8 & 23 & 15.4 & 19 & 12.8 & 149 \\
\hline Don't know & 9 & 3.4 & 178 & 67.9 & 52 & 19.8 & 23 & 8.8 & 262 \\
\hline Total & 58 & 4.3 & 966 & 71.3 & 213 & 15.7 & 118 & 8.7 & 1355 \\
\hline
\end{tabular}

$\chi^{2}=73.31, d f=72, P=0.35$

${ }^{a}$ Low income $\leq 200$ Jordanian dinars (JD) per month; medium income 201-600 JD per month; high income $\geq 600$ JD per month. 


\begin{tabular}{|c|c|c|c|c|c|c|c|c|c|}
\hline \multirow[t]{2}{*}{ Employment status } & \multicolumn{2}{|c|}{ Underweight } & \multicolumn{2}{|c|}{ Normal } & \multicolumn{2}{|c|}{ Overweight } & \multicolumn{2}{|c|}{ Obesity } & \multirow{2}{*}{$\begin{array}{c}\text { Total } \\
\text { No. }\end{array}$} \\
\hline & No. & $\%$ & No. & $\%$ & No. & $\%$ & No. & $\%$ & \\
\hline \multicolumn{10}{|l|}{ Father employed } \\
\hline Yes & 44 & 4.8 & 636 & 68.9 & 157 & 17.0 & 86 & 9.3 & 923 \\
\hline No & 14 & 3.2 & 330 & 76.4 & 56 & 13.0 & 32 & 7.4 & 432 \\
\hline \multicolumn{10}{|l|}{ Mother employed } \\
\hline Yes & 10 & 4.5 & 154 & 69.4 & 25 & 11.3 & 33 & 14.9 & 222 \\
\hline No & 48 & 4.2 & 812 & 71.7 & 188 & 16.6 & 85 & 7.5 & 1133 \\
\hline Total & 58 & 4.3 & 966 & 71.3 & 213 & 15.7 & 118 & 8.7 & 1355 \\
\hline
\end{tabular}

Father employed: $\chi^{2}=47.9, d f=1, P<0.001$ (overweight); $\chi^{2}=24.7, d f=1, P<0.001$ (obesity). Mother employed: $\chi^{2}=24.7, d f=1, P<0.001$ (overweight); $\chi^{2}=22.9, d f=1, P<0.001$ (obesity).

Irbid governorate. It would be expected that the nutritional status of adolescents this governorate in the north of Jordan is different from other governorates in the central or southern parts of Jordan. The central region of Jordan includes the capital city, Amman, where it is likely that the average socioeconomic status is higher, the percentage of working mothers is higher and students are exposed to a greater number of fast-food restaurants. In contrast, in the southern region of Jordan socioeconomic status i slower, thepercentage of working mothers is lower and students are more likely to benefit from home-cooked meals,

The prevalence of overweight and obesity in our study in the north of Jordan is higher than in some developed countries, where the prevalence of overweight and obesity among adolescents was shown to be $16.3 \%$ in the United States [9], 19.6\% in Canada [10] and $22.7 \%$ in France [11]. However, in developing countries the picture is more complicated. The prevalence of overweight and obesity among adolescents in this study is higher than a study in India showing a rate of $16.8 \%$ among adolescents [12], but is less than in some other Arab countries, for example in Kuwait, where the prevalence of overweight and obesity among children was 50\% [13] and in the United Arab Emirates, where it was 27\% [8]. The reasons behind this may be the dietary habits in those Arab countries, where there is a high consumption of dates and carbohydrate-rich food. At the same time as lifestyles worldwide are becoming more sedentary, the hot climate of Arab countries exacerbates the problem as it discourages people from participating in sports and other physical activities, cars are used for even short-distance travel and there is a tradition of taking afternoon naps after meals [14].

It is notable that the prevalence of overweight was higher among female students than male students, while the prevalence of obesity was higher among male than female students. This might be due to the different physiological composition of the female body or because female adolescents are more likely to try to control their weight to prevent obesity. While the study in France revealed no gender differences [11], a study in Canada showed that the prevalence of overweight and obesity was greater in boys than girls [10].

The prevalence of overweight and obesity among adolescents in urban areas was higher than in rural areas. An explanation might be that adolescents in urban areas eat more fast-food than adolescents in rural areas, since more restaurants are available in urban areas and less time is available for working mothers to cook traditional meals at home. The study results are consistent with a study in China showing that obesity was more prevalent in urban areas [9], but they disagree with studies conducted in the United States and Russia where obesity was higher in rural areas [9]. This may be because walking and bicycling are more practical and safe in urban areas in more developed countries or because health promotion programmes about exercise and diet are more focused in urban than rural communities in these countries.

The prevalence of overweight and obesity among students with working fathers and mothers in the present study was significantly higher than among those with nonworking fathers and mothers. Furthermore, the prevalence rose with risingfamilyincomes, although the difference did not reachstatisticalsignificance. Even so, the difference among the 3 income groups suggests that the prevalence of overweight and obesity increases as socioeconomic status rises. The influence of socioeconomic status on adolescents' lifestyles could be one reason. For example, diet and physical activity may differ; adolescents of high socioeconomic status (especially those with working mothers) have greater access to packaged and fast food and depend on automobiles for transport, while those of lower socioeconomic status (especially those with nonworking mothers) have access to more homecooked meals and are more likely to walk to school.

The results of the present study are consistent with a study in another rapidly developing country, China, which indicated that as socioeconomic status rises, the prevalence of overweight and obesity increases [9]. The results 
contrast, however, with data from the United States and Russia [9], which the prevalence of overweight and obesity decreases with higher socioeconomic status. In some developed countries the cost of food that is high in fat and sugar, especially fast food, is low in comparison with more traditional foods, and therefore affordable by people of low socioeconomic status. However, in Jordanian culture, fast-food restaurants are relatively expensive and eating there is affordable mainly by high socioeconomic status families.

The results cannot be generalized to Jordan as a whole because this study was conducted only in the northern part of Jordan. The sample consisted of adolescents studying in the 8th to 10th grades, which make it hard to generalize to adolescents in other grades. Furthermore, the percentage of participant students who lived in rural areas was higher than the percentage in the total population.

\section{Conclusions}

The current study documented a high prevalence rate of overweight and obesity among male and female adolescents aged 13-16 years old in Irbid governorate. This finding is a serious concern for public health in Jordan and calls for the creation of new prevention programmes at the individual, family and community level. More research is needed on the behavioural and biological causes of overweight and obesity, and on the prevalence among different regions and settings. Further research is also needed at the national level to identify the characteristics of individuals who have successfully maintained normal weight over the long term.

\section{References}

1. IOTF demands action on childhood obesity crisis. International Obesity TaskForce, 2007 [press release] (http://www.iotf.org/ media/IOTFmay12.htm, accessed 27 January 2010).

2. Obesity and overweight. World Health Organization [online factsheet] (hthttp://www.who.int/mediacentre/factsheets/ fs311/en/index.html, accessed 27 January 2010).

3. Goossens L, Braet C, Decaluwe V. Loss of control over eating in obese youngsters. Behavior research and therapy, 2007, 45(1):1-9.

4. Ajlouni $\mathrm{K}$, Jaddou H, Batieha A. Obesity in Jordan. International journal of obesity, 1998, 22(7):624-8.

5. Main index. Jordan Department of Statistics [website] (http:// www.dos.gov.jo/dos_home_a/main/index.htm, accessed 27 January 2010).

6. Multipurpose family survey analytic report. Jordan Department of Statistics [website] (http://www.dos.gov.jo/sdb_pop/ sdb_pop_a/ehsaat/analytical/analyt_a.htm, accessed 27 January 2010).

7. About BMI for children and teens. Atlanta, Georgia, Centers of Disease Control and Prevention, 2007 [online factsheet] (http://www.cdc.gov/nccdphp/dnpa/bmi/childrens_BMI/ about_childrens_BMI.htm\#What\% 20is\%20BMI\%20percentile, accessed 27 January 2010).
8. Kerkadi A, Aboelnaga N, Ibrahim W. Study of overweight and associated risk factors among primary female school children in Al-Ain city United Arab Emirates. Emirates journal of agriculture sciences, 2005, 17(1):43-56.

9. Wang Y. Cross-national comparison of childhood obesity: The epidemic and the relationship between obesity and socioeconomic status. International journal of epidemiology, 2001, 30:1129-36

10. Janssen I et al. Overweight and obesity in Canadian adolescents and their associations with dietary habits and physical activity patterns. Journal of adolescent health, 2004, 35(5):360-7.

11. Klein-Platat $\mathrm{K}$ et al. Prevalence and sociodemographic determinants of overweight in young French adolescents. Diabetes metabolic research review, 2003, 19:153-8.

12. Ramachandran A et al. Prevalence of overweight in urban Indian adolescent school children. Diabetes research and clinical practice, 2002, 57(3):185-90.

13. Sorkhou I et al. Juvenile hypertension in Kuwait: prevalence and influence of obesity. International pediatrics, 2003, 18(3):178-84.

14. El-Hazmi M, Warsy A. The prevalence of obesity and overweight in 1-18-year-old Saudi children. Annals of Saudi medicine, 2002, 22(5-6):303-7. 